\title{
The reliability of an arabic version of the self- administered standardized chronic respiratory disease questionnaire (CRQ-SAS)
}

\author{
Mohamed S Al Moamary ${ }^{*}$ and Hani M Tamim
}

\begin{abstract}
Background: To produce a conceptually equivalent Arabic version to the original Self-Administered Chronic Respiratory Disease Questionnaire with standardized dyspnea domain (CRQ-SAS) and to assess its reliability.

Methods: The study was carried out in two stages: stage I which was the translation of the CRQ-SAS questionnaire from the English to the Arabic language, and stage II which represented the test-retest reliability for patients receiving usual care for COPD who were not yet admitted to the pulmonary rehabilitation program.

Results: Forty five patients with stable COPD were enrolled in this study. Strong test-retest reliability was found for the four domains of the CRQ-SAS, with the intra-class correlation coefficient of 0.97 for each of the domains. The association between most parameters and the four domains of CRQ-SAS were not found to be statistically significant, as measured by Pearson correlation. The number of exacerbations was negatively correlated with the dyspnea domain (correlation $=-0.36, p$-value $=0.02$ ). The disease duration was negatively correlated with the domain fatigue (correlation $=-0.35, \mathrm{p}$-value $=0.02$ ). The correlation between FEV1/FVC ratio and emotion domain was $-0.30(p$-value $=0.05)$. The mastery domain was negatively correlated with FEV1/FVC ratio with a correlation of -0.27 with borderline statistical significance ( $p$-value $=0.07$ ).
\end{abstract}

Conclusion: The Arabic translation of the CRQ-SAS was found to be reliable to assess the quality of life among patients with COPD.

Keywords: Quality of Life Pulmonary rehabilitation, COPD, Saudi Arabia

\section{Background}

The concept of quality of life has added a new dimension to the measurement of modalities outcomes used in the management of different diseases. Health-related quality of life (HRQL) is measured by instruments specifically developed to assess the experiences of patients with diverse diseases [1]. These instruments vary from general to disease-specific such as Chronic Respiratory Disease Questionnaire (CRQ) $[2,3]$. The CRQ is a disease specific questionnaire utilized to assess HRQL for chronic respiratory diseases such as chronic obstructive pulmonary disease (COPD), bronchiectasis, and interstitial lung diseases. It is considered to be valid, precise, simple to use, and sensitive to change in clinical status

\footnotetext{
*Correspondence: almoamary@yahoo.com
College of Medicine, King Saud bin Abdulaziz University for Health Sciences,

* Correspondence: almoamary@yahoo.com
College of Medicine, King Saud bin Abdulaziz University for Health Sciences, Riyadh, Saudi Arabia
}

(c) 2011 Al Moamary and Tamim; licensee BioMed Central Ltd. This is an Open Access article distributed under the terms of the Creative

and covers the domains of dyspnea, emotion, fatigue, and mastery [4-7]. The original CRQ was interviewer dependent (CRQ-IA) and was made available with both individualized and standardized dyspnea domain. Though CRQ-IA helps to avoid missing items and errors, it has the drawback that it should be administrated by an interviewer and may be time consuming $[3,8]$. This has led to the development of the CRQ - Self Administrated with standardized dyspnea domain (CRQ-SAS) $[9,10]$. Respondents were asked to grade their function in each item using a seven-point likert scale. The total score for each domain was divided by the number of items answered, yielding a potential score of one to seven, with higher numbers representing better function. Moreover, Schunemann et al. reported that CRQ-SAS did not impair validity and proved to have more responsiveness when compared to CRQ-IA [11]. 
The Arabic language is spoken by approximately 200 million people. The HRQL questionnaires are not yet widely utilized as an outcome measurement in Arabic speaking countries. This has raised the need for the availability of an Arabic version of an HRQL instrument which is socially and culturally sensitive and acceptable. Therefore, the objective of this study was to produce a conceptually equivalent Arabic version to the original CRQ-SAS with standardized dyspnea domain and to assess its reliability.

\section{Methods}

The study was carried out at King Abdulaziz Medical City (KAMC), Riyadh, Saudi Arabia, which is a tertiary care teaching facility of approximately 1000 bed capacity. The study was carried out in two stages: stage I which was the translation of the CRQ-SAS questionnaire from the English to the Arabic language, and stage II which was the assessment of the test-retest reliability for patients receiving usual care for COPD who were not yet admitted to the pulmonary rehabilitation program (PR).

\section{Stage I: Translation}

The process was commenced by translating the CRQSAS from the source language (English) to the target language (Arabic). The forward translation was conducted by two certified local translators. Both produced independent translation form the source to the target language. Apart from clarification of some medical terminology, the translators have found no difficulty during translation. After consultation with the translators, the primary author re-conciliated a first Arabic version that was considered conceptually equivalent to the source language. Another two certified translators, who were blinded to the source documents, carried out the back translation from Arabic to English. Both produced independent translation from the target language (first version of CRQ-SAS) to the source language. The primary author compared the two translations with the source CRQ-SAS. The back translation version and the original source document were reviewed by the owner of CRQSAS. Based on the received comments, a final Arabic version was produced. Finally, a pilot test was carried out on 5 patients to ensure that the final draft is clear and understandable. Based on this testing, we have finalized the Arabic version of the CRQ-SAS.

\section{Stage II: Test - retest reliability}

The test-retest reliability was conducted at the outpatient pulmonary clinic and the PR program at the KAMC-Riyadh. It was carried out by recruiting a total of 45 patients attending either of the above mentioned departments. The inclusion criteria were: age $\leq 75$ years, clinical diagnosis of COPD in a stable condition for at least 4 weeks, the ratio of forced expiratory volume in one second over forced expiratory volume $\left(\mathrm{FEV}_{1} / \mathrm{FVC}\right.$ ratio) $\leq 70 \%$ and $\mathrm{FEV}_{1} \leq 70 \%$, and free of significant handicapping disease. After signing the informed consent form, patients were interviewed and physically examined as part of their routine management. The Arabic version of the CRQ-SAS was initially self-administrated to the patients. The re-test session was arranged after 3-5 weeks taking in consideration that they were in a stable clinical condition. Moreover, patients underwent different standard tests that included: measurement of $\mathrm{FEV}_{1}, \mathrm{FVC}, \mathrm{FEV}_{1} / \mathrm{FVC}$ ratio, residual volume (RV), total lung capacity (TLC), arterial saturation by pulse oximeter, and the 6-minute walking test $(6 \mathrm{MWT})$ as per American Thoracic Society criteria [12,13]. Pulmonary function test would normally be done within two weeks from the 6MWD and CRQ-SAS to avoid exhausting patients. This study received the approval of the institute review board of King Abdullah International Centre for Medical Research (KAIMRC), the research arm of our health organization.

\section{Statistical analysis}

The statistical analyses carried for stage II of this study are presented in this subsection. Data were entered into the Statistical Package for Social Sciences (SPSS) version 16 , which was used for the data management and analyses. Continuous variables were summarized by calculating the mean and its standard deviation, whereas categorical variables were summarized by the number and percent. Pearson correlation coefficients were calculated for the different measures of the CRQ-SAS and the different baseline characteristics. Reliability analysis was carried out by calculating the intraclass correlation coefficient for the test-retest reliability of the Arabic version of the CRQ-SAS. A value of 0.7 was considered acceptable both for Crohnbach's alpha and the intraclass correlation coefficient.

\section{Results}

Forty five patients with stable COPD were enrolled in this study. Their average age was $63.3 \pm 8.8$ years and ranging between 44-75 years. There were 19 female patients $(42.2 \%)$ and 26 male patients $(57.8 \%)$. The average disease duration was 13.9 years \pm 7.1 (range from 4 to 30). The smoking history reflected as the pack-year was found to be $39.7 \pm 35.8$ (range from 0 to 150). The average number of exacerbations over the past 12 months was found to be $3.8 \pm 2.5$ (range from 1 to 10 ), whereas the number of admissions was $1.2 \pm 1.4$ (range from 0 to 5 ). The average body mass index for the subjects was $32.6 \pm 9.3$ (range from 18.4 to 52.4 ). The $\mathrm{FEV}_{1}, \mathrm{FVC}$, and $\mathrm{FEV}_{1} / \mathrm{FVC}$ ratio were $58.4 \% \pm 15.3$ 
Table 1 Intraclass correlation coefficients between baseline and follow-up as an assessment of the test-retest reliability of the 45 consecutive patients with COPD enrolled in the study (mean \pm standard deviation, and range)

\begin{tabular}{lccc}
\hline Domain & $\begin{array}{c}\text { Test Score } \\
\text { Meandard deviation } \\
\text { (range) }\end{array}$ & $\begin{array}{c}\text { Re-test Score } \\
\text { Mean standard deviation } \\
\text { (range) }\end{array}$ & Intraclass correlation \\
\hline Dyspnea & $4.9 \pm 1.3$ & $5.0 \pm 1.3$ & 0.97 \\
& $(2.4-7.0)$ & $4.4-6.8)$ & 0.97 \\
\hline Fatigue & $4.6 \pm 1.1$ & $(2.6-7.0)$ & 0.97 \\
\hline Emotions & $(2.5-6.9)$ & $5.1 \pm 1.0$ & $(3.3-7.0)$ \\
\hline Mystery & $5.0 \pm 1.0$ & $5.3 \pm 1.0$ & 0.97 \\
& $(3.2-7.0)$ & $(3.0-6.9)$ & \\
\hline
\end{tabular}

(range from 25 to 78 ), $70.1 \% \pm 12.7$ (range from 32 to 85 ), and $61.7 \pm 8.8$ (range from 38 to 78 ), respectively. The total lung capacity was $90.4 \% \pm 14.8$ (range from 71 to 145 ). $6 \mathrm{MWD}$ was 226.9 meter \pm 99.2 (range from 50 to 400). Finally, pertaining to the medications, it was found that 41 patients (91.1\%) used an inhaled corticosteroid agent, $42(95.6 \%)$ used a long acting beta agonist agent, and 30 (66.7\%) used tiotropium bromide.
The time difference between test-retest CRQ administrations was $4 \pm 0.8$ weeks. Table 1 presents the intraclass correlation coefficients, as well as the means and standard deviations, between the baseline and follow-up as an assessment of the test-retest reliability. Strong test-retest reliability was found for the four domains of the CRQ-SAS, with the correlation coefficient of 0.97 for each of the domains. Figure 1 presents the scatter
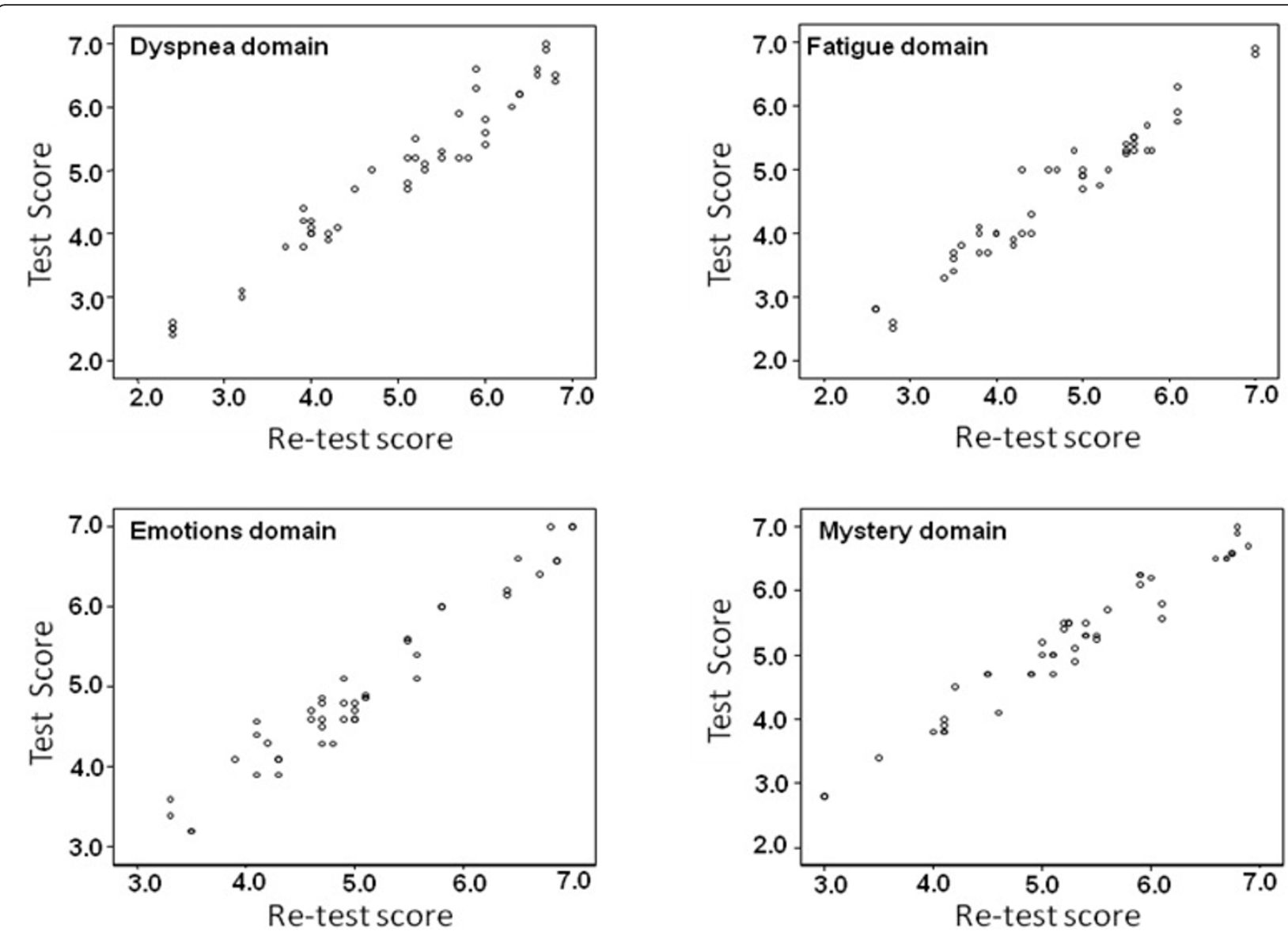

Figure 1 A scatter plot for the responses of the subjects on the 4 domains of the chronic respiratory disease questionnaire. 
Table 2 Correlations between the initial score of the four domains of CRQ and selected parameters

\begin{tabular}{lllll}
\hline & Dyspnea* $^{*}$ & Fatigue* $^{*}$ & Emotion* $^{*}$ & Mastery* $^{*}$ \\
\hline Age & $0.02(0.88)$ & $0.07(0.65)$ & $0.05(0.75)$ & $0.11(0.49)$ \\
\hline Disease duration & $-0.23(0.13)$ & $-0.35(0.02)$ & $-0.25(0.10)$ & $-0.09(0.58)$ \\
\hline Number of exacerbations over twelve months & $-0.36(0.02)$ & $-0.02(0.88)$ & $-0.002(0.99)$ & $-0.07(0.66)$ \\
\hline Number of admissions over twelve months & $-0.18(0.23)$ & $-0.06(0.68)$ & $-0.03(0.85)$ & $-0.20(0.18)$ \\
\hline Smoking history (Pack-year) & $-0.04(0.77)$ & $-0.17(0.26)$ & $-0.13(0.39)$ & $-0.20(0.19)$ \\
\hline The percentage of Forced Expiratory volume in one second (FEV $\left.)_{1}\right)$ & $0.08(0.59)$ & $0.18(0.25)$ & $-0.07(0.64)$ & $0.02(0.91)$ \\
\hline FEV1/FVC ratio & $-0.02(0.91)$ & $-0.20(0.19)$ & $-0.30(0.05)$ & $-0.27(0.07)$ \\
\hline Six minutes walk distance (meter) & $-0.02(0.92)$ & $0.06(0.69)$ & $0.05(0.76)$ & $-0.05(0.76)$ \\
\hline Body mass index & $-0.12(0.45)$ & $-0.26(0.08)$ & $-0.10(0.50)$ & $0.0(1.00)$ \\
\hline *
\end{tabular}

*correlation ( $p$ value)

plot for the Reponses of the subjects on the 4 domains of the CRQ-SAS, which indicates high correlation.

Table 2 presents the correlations between selected parameters and the four domains of CRQ-SAS. Most of the correlations calculated were not found to be statistically significant. On the other hand, number of exacerbations over the past 12 months was found to be negatively correlated with the dyspnea domain (correlation $=-0.36$, $\mathrm{p}$-value $=0.02$ ). The disease duration was also found to be negatively correlated with the domain fatigue (correlation $=-0.35, \mathrm{p}$-value $=0.02$ ). The correlation between $\mathrm{FEV}_{1} / \mathrm{FVC}$ ratio and emotion domain was -0.30 ( $\mathrm{p}$-value $=0.05)$. Finally, the mastery domain was also negatively correlated with $\mathrm{FEV}_{1} / \mathrm{FVC}$ ratio with a correlation of -0.27 , which was found to be of borderline statistical significance $(p$-value $=0.07)$. Both the $\mathrm{FEV}_{1}$ and the 6MWD did not show significant correlation with any of the domains.

\section{Discussion}

The present study confirms that the Arabic version of the CRQ-SAS performed well and was reliable with a strong interclass co-relation. Moreover, to the author's knowledge, the current study is the first that ever assessed the quality of life of patients with COPD from Saudi Arabia. This concept of HRQL was not commonly practiced in the Middle East as reflected by the scanty data that came from this region. Its importance rose from the fact that physiological measures may not sufficiently assess functional outcomes of interventions implemented for COPD where HRQL instruments can serve this purpose [1,3].

The instruments that measure HRQL for COPD could be either disease specific or general in nature. When compared to general tools, the disease specific instruments are more responsive and may be more valid to both clinician and patients [1,7]. An effective instrument should be valid, interpretable, responsive, and reliable $[14,15]$. The CRQ which was developed in 1987 is one of the most commonly used tools to assess HRQL in patients with COPD that fulfill the aforementioned criteria $[7,13]$. Though the original CRQ was simple to use, it was time consuming as it is interviewer dependent with individualized dyspnea domain. In one study, the time required to complete the CRQ-SAS was reduced to half the time required for the CRQ-IA [16]. This is partly related to the standardization of the items related to the dyspnea domain. The CRQ-SAS is constituted of 20 items that cover four domains: dyspnoea with 5 questions, fatigue with 4 questions, emotion with 7 questions, and mastery (Feeling of control over the disease) with 4 questions. The brevity of the CRQ-SAS with standardized dyspnea domain was considered to be an attractive alternative as it is also valid, reliable, and responsive $[10,12]$.

A valid translation is essential to achieve a HRQL instrument that functions well in a different environment from its original setting. This carries more

Table 3 Comparison of the different studies in the literature that assessed the health related quality by CRQ-SAS and the current one

\begin{tabular}{lllccccc}
\hline Study & Year & Country & FEV & Dyspnea & Fatigue & Emotions & Mastery \\
\hline Williams et al [10] & 2001 & UK & 1.13 L & 2.4 & 3.3 & 4.4 & 4.2 \\
\hline Puhan et al [12] & 2004 & Multinational & $45.1 \%$ & 3.6 & 3.8 & 4.1 & 4.25 \\
\hline Schunemann et al [13] & 2005 & Canada/USA & $45.4 \%$ & 4.1 & 3.9 & 4.7 & 4.6 \\
\hline Oh et al [23] & 2009 & Korea & $52.3 \%$ & 4.4 & 4.0 & 4.6 & 5.2 \\
\hline Al-Moamary et al (current study) & 2009 & Saudi Arabia & $58.4 \%$ & 4.9 & 4.6 & 5.0 & 5.2 \\
\hline
\end{tabular}


importance in questionnaires that assess a wide spectrum of domains like CRQ. Arabic Language is spoken in 21 countries which necessitate paying attention to the slight differences related to variations in the accents of various regions. Our translation was adapted to the region of the six countries of the Gulf Cooperation Council (Bahrain, Kuwait, Oman, Qatar, Saudi Arabia, and United Arab Emirates). The lengthy process of translating CRQ-SAS to Arabic has resulted in the adaptation of a conceptually equivalent Arabic version to the original CRQ-SAS. The achieved test-retest reliability in our study reflects stability over time while the strong internal consistency reflects stability across the items of each domain. Similar finding were achieved by the translation of CRQ to other languages like Dutch, Spanish, French-Canadian, and Korean [16-19]. When compared to other studies, patients with COPD from Saudi Arabia were affected by their disease as reflected by measuring their quality of life by CRQ-SAS (Table 3).

Similar to the findings in the literature, our study showed lower correlations between CRQ domains with the nature of COPD and pulmonary function parameters $[3,18,20]$. In our study, dyspnea was highly correlated to the number of execrations which reflects a disease that either advanced or poorly controlled $[21,22]$. Dyspnea was not linked with pulmonary function, a finding supported by other studies [17,22]. Fatigue domain was highly correlated with disease duration, while both emotion and mastery domains were correlated with a more severe disease as reflected by FEV1/ FVC ratio. Guell et al found higher correlation between the last two domains and pulmonary function [17]. The domains of emotion, fatigue, and mastery were associated with anxiety and depression, findings that are commonly observed in patient with either advanced disease or longer disease duration. Despite documented correlation of CRQ-SAS with the 6MWD, our finding did not show such correlation [10,12,13,23]. A finding that can be explained with higher $\mathrm{FEV}_{1}$ in our study when compared to other studies shown in table 3 and the need to a larger study sample to verify the lack of correlations.

Finally, we would like to mention some limitations of the current study. Due to unavailability of a gold standard test to assess HRQL for patients with COPD by a valid linguistic translation of similar instruments, this study was limited to the reliability of the CRQ-SAS and not extended to assess its validity. Though we belief that the lack of priori hypotheses can be claimed to conclude sufficient validity. Moreover, responsive of the Arabic version of CRQ-SAS to change was not planned in the design of the study and merit further studies to assess this aspect.

\section{Conclusion}

The Arabic translation of the CRQ-SAS was found to be reliable among patients with COPD. It can also perform well to assess their HRQL in a manner similar to the original CRQ-SAS.

\section{Acknowledgements}

This study received financial support from KAIMRC, Riyadh, Saudi Arabia. The authors would also like to acknowledge the effort of Mrs. Amal Alshami and Miss Monira Aldhahi for collecting patients' data and follow-up the administration of the CRA-ASA.

\section{Authors' contributions}

MA-M is the principle investigator who contributed in study design, getting approval, patients recruitment, data collection and analysis, writing the paper, and submission. HT has contributed in study design, data analysis, and writing the paper.

\section{Competing interests}

The authors declare that they have no competing interests.

Received: 9 September 2010 Accepted: 28 April 2011

Published: 28 April 2011

\section{References}

1. Guyatt GH, Feeny DH, Patrick DL: Measuring health related quality of life. Ann Intern Med 1993, 118:622-629.

2. Wijkstra P, Vergert E, Altena R, Otten V, Postma D, Kraan J, Koeter G: Reliability and validity of the chronic respiratory questionnaire (CRQ). Thorax 1994, 49:465-467.

3. Guyatt GH, Berman LB, Townsend M, Pugsley So, Chambers LW: A measure of quality of life for clinical trials in chronic lung disease. Thorax 1987, 47:773-778.

4. Marcia A, Simonson D: Assessment of quality-of-life. N Engl J Med 1996, 334:835-840.

5. Redelmeier DA, Guyatt GH, Goldstein RS: Assessing the minimal important difference in symptoms: a comparison of two techniques. J Clin Epidemiol 1996, 49:1215-9.

6. Singh SJ, Sodergren SC, Hyland ME, Williams J, Morgan MD: A comparison of three disease-specific and two generic health-status measures to evaluate the outcome of pulmonary rehabilitation in COPD. Respir Med 2001, 95:71-7.

7. Wyrwich K, Fihn S, Tierney W, Kroenke K, Babu A, Wolinsky F: Clinically important changes in health-related quality of life for patients with chronic obstructive pulmonary disease: an expert consensus panel report. J Gen Intern Med 2003, 18:196-202.

8. Jones P: Issues concerning health-related quality of life in COPD. Chest 1995, 107:187S-193S

9. Schunemann HJ, Griffith L, Jaeschke R, Goldstein R, Stubbing D, Austin P, Guyatt GH: A Comparison of the Original Chronic Respiratory Questionnaire With a Standardized Version. Chest 2003, 124:1421-1429.

10. Williams JE, Singh SJ, Sewell L, Guyatt GH, Morgan MD: Development of a self-reported Chronic RespiratoryQuestionnaire (CRQ-SR). Thorax 2001 56:954-959.

11. Schunemann HJ, Goldstein R, Mador MJ, McKim D, Stahl E, Puhan M, Griffith LE, Grant B, Austin P, Collins R, Guyatt GH: Eur Respir J 2005, 25:31-40.

12. Standardization of Spirometry, 1994 Update: American Thoracic Society. Am J Respir Crit Care Med 1995, 152:1107-1136.

13. Brooks DS, Gibbons WJ: ATS statement on six-minute walk test. Am J Respir Crit Care Med 2003, 167:1287.

14. Chauvin A, Rupley L, Meyers K, Johnson K, Eason J: Outcomes in Cardiopulmonary Physical Therapy: Chronic Respiratory Disease Questionnaire (CRQ). Cardiopulm Phys Ther J 2008, 19:61-67.

15. Moran L, Guyatt G, Norman G: Establishing the minimal number of items for a responsive, valid, healthrelated quality of life instrument. J Clin Epidemiol 2001, 54:571-579. 
16. Puhan MA, Behnke M, Laschke M, Lichtenschopf A, Brandli O, Guyatt G, Schunemann HJ: Self-administrationand interviewer-administration of the chronic respiratory questionnaire: A randomized trial in three Germanspeaking countries. Respir Med 2004, 98:342-350.

17. Güell R, Casan P, Sangenís M, Morante F, Belda J, Guyatt G: Quality of life in patients with chronic respiratory disease: the Spanish version of the Chronic Respiratory Questionnaire (CRQ). Eur Respir J 1998, 11:55-60.

18. Bourbeau J, Maltais F, Rouleau M, Guimont C: French-Canadian version of the Chronic Respiratory and St Georg's Respiratory questionnaire: An assessment of their psychometric properties in patients with chronic respiratory pulmonary disease. Can Respir J 2004, 11:480-486.

19. Guyatt G, Townsend M, Keller J, Singer J, Nogradi S: Measuring functional status in chronic lung disease: conclusions from a randomized control trial. Respir Med 1989, 83:293-297.

20. Aaron S, Vandemheen K, Clinch J, Ahuja J, Brison RJ, Dickinson G, Hébert PC: Measurement of short-term changes in dyspnea and diseasespecific quality of life following an acute COPD exacerbation. Chest 2002, 121:688-696.

21. Wilson CB, Jones PW, O'Leary CJ, Cole PJ, Wilson R: Validation of the St. George's Respiratory Questionnaire in bronchiectasis. Am J Respir Crit Care Med 1997, 156:536-541.

22. Hajiro T, Nishimura K, Tsukino M, Ikeda A, Koyama H, Izumi T: Comparison of discriminative properties among disease-specific questionnaires for measuring health-related quality of life in patients with chronic obstructive pulmonary disease. Am J Respir Crit Care Med 1998, 157:785-790.

23. Oh EG, Bang SY, Kim YS, Park MS, Kim SK: Health-related quality of life among Koreans with chronic respiratory disease. Int I Tuberc Lung Dis 2009, 13:580-586.

\section{Pre-publication history}

The pre-publication history for this paper can be accessed here:

http://www.biomedcentral.com/1471-2466/11/21/prepub

doi:10.1186/1471-2466-11-21

Cite this article as: Al Moamary and Tamim: The reliability of an arabic version of the self-administered standardized chronic respiratory disease questionnaire (CRQ-SAS). BMC Pulmonary Medicine 2011 11:21.

\section{Submit your next manuscript to BioMed Central and take full advantage of:}

- Convenient online submission

- Thorough peer review

- No space constraints or color figure charges

- Immediate publication on acceptance

- Inclusion in PubMed, CAS, Scopus and Google Scholar

- Research which is freely available for redistribution

Submit your manuscript at www.biomedcentral.com/submit
Biomed Central 